\title{
A STUDY ON DUAL CLUTCH TRANSMISSION
}

\section{P. P. PATNAIK* \& BHABANI S. MAHANTO}

ITER, Siksha 'O'Anusandhan Deemed to be University, Bhubaneswar, Odisha, India

\section{ABSTRACT}

Aim of this paper is to ponder the double grasp transmission in detail. A Dual grip transmission (DCT) is a kind of customized transmission, included with a twofold handle module and two data shafts. A DCT can give a magnificent gear moving with a mechanical assembly pre-decision method and covering of handle responsibility. The device pre-decision procedure suggests that the synchronization of the moving toward mechanical assembly has been done before the genuine device moving method starts. Additionally, on account of the covering segment of the two grasps, torque is traded from the engine to the driving wheels without impedance in the midst of outfit moving. In this manner, it gives a quick mechanical assembly moving without yielding eco-kind disposition and riding comfort. In development, with an unquestionably figured and definitely controlled slippage of the twofold handle module, the DCT can give a speedy and smooth apparatus moving. The execution of a DCT in the midst of outfit moving relies upon a specially created handle duty controller. An average handle responsibility controller should have the ability to achieve (1) a snappy hold to-get a handle on moving and (2) a smooth mechanical assembly moving without detectable torque agitating impact. This investigation work proposes an as of late laid out handle to-hold moving controller that satisfies the two goals determined beforehand. The displayed control law is realized in an immediate 9 control system that unequivocally disengages the controlling of the two handles. The displayed control procedure can be associated with a broad assortment of usages with straightforward execution and a tolerable energy. PC propagations in Simulink showed that the control objectives were recognized with a fiery and tolerably essential controller. According to the amusement results, the ordinary degrees of the yield torques were diminished by $32.5 \%$ with the assistance of the proposed handle to-hold control law. Similarly, by viewing a couple of contrast re-institutions, we found that the yield torque refinement ended up greater as the grip actuator time reliable wound up greater. Moreover, re-sanctioning outcomes exhibited that tinier handle weight changing rate added to a smoother adjust moving.

KEYWORDS: Automobile, Control Methodology, Dual Clutch Transmission, Gear, Gear Move Administer \& Torque

Received: Mar 02, 2019; Accepted: Apr 23, 2019; Published: Jun 25, 2019; Paper Id.: IJMPERDJUN2019193

\section{INTRODUCTION}

In the vehicle business, the modified transmission has for quite a while been seen as a substitute for manual transmission. As a key execution marker of vehicle, the financial execution of vehicle fills has been gradually regarded, and the control arrangement of vehicle's customized transmission is fundamental[1].

The progression example of customized transmission is generally reflected in such points of view as wonderful economy and comfort of driving and so forth[2].

To pick the reasonable mechanical assembly through the cooperation between the objective of the driver and the controller of the vehicle, low fuel use can be recognized in most undertaking examples of the engine, while the control of the transmission of the standard customized transmission is recognized through the control of torque converter and a planetary gear set. Disregarding the way that follows a long time of progress, the profitability of 
mechanical transmission is still lower than that of the manual transmission[3]. Hence, the basic goal of the vehicle business is to upgrade the mechanical efficiency, and meanwhile, to ensure the comfort and high gauge of modified gearshift[4] [5]. Generally, vehicle transmission systems have combined either a lone hold or a torque converter between the engine and the drivetrain. These empower the engine to run while the vehicle is exceptionally still without the engine backing off. To date most of purchaser vehicles have featured either a manual transmission or an epicyclical modified transmission, while couple of vehicles have intertwined always factor transmission (CVT) systems. Starting late, in any case, a creating number of makers have been making and manufacturing twofold handle transmissions(DCT) for use on customer vehicles [6]. This kind of transmission offers benefits over both standard manual transmissions and epicyclical modified transmissions. This report explores the development used in DCT structures and the focal points which such systems give[7].

\section{DCT - WORKING}

A DCT system relies upon a standard manual gearbox yet incorporates two separate holds, a drive handle and a non-drive handle [6]. Correspondingly, there are two data shafts where an ordinary manual gearbox would simply have one. Whenever the drive grasp is related with a mechanical assembly from the apparatus train, offering drive to the wheels. Meanwhile the non-drive handle is related with the accompanying device to be used [8]. Exactly, when the driver needs to change gear the drive handle and non-drive hold are swapped over. This ensures the anticipated next apparatus is always pre-selected. The even numbered riggings are mated to one grasp, while the odd numbered apparatuses are mated to the following. This licenses back to back gear moving to happen, yet suggests that the driver can't miss a device as is possible with a manual rigging box, for example switching from fourth gear to second mechanical assembly[9]. The contraption change can be begun normally, copying the value of a standard customized gearbox and utilizing an electronic control structure. On the other hand, the device change can be constrained by the driver by methods for a 'Tiptronic-style' adjust switch setup, thusly rehashing the convenience of a mechanized or grasp less manual gearbox[10]. The twin weight driven holds are regularly packaged together as a singular unit, and the entire gear move is controlled normally by the electronic control unit, which controls the initiation of the grip hydrodynamics. On vehicle begin; first contraption starting now is secured. There is no torque traded to the wheels, regardless, as the essential handle, associated with the odd numbered riggings, is open. Right when development is begun by the driver picking either totally customized 'D' mode or using the gear selector to associate first contraption, the electronic controller actuates the water driven unit which closes the chief grasp. As the grip plates come into slipping contact, the engine torque is traded to the wheels by methods for the mechanical assembly set and related synchronisers, giving drive. Second gear is starting at now preselected and joined to the second handle, which is open and not trading torque. On beginning an upshift the principle handle pulls back as unclear speed from the second grasp associates with [11]. This allows a reliable torque change between the two apparatus consolidates, and allows persevering drive in the midst of the gear change process. This is a glaring distinction to a manual gearbox where there is no torque trade from the engine to the wheels while outfit changes are being performed. At the point when handle one is isolated, third mechanical assembly can be preselected and added to the essential grasp which is then arranged to swap over with the second hold to complete the advancement from second apparatus to third. Writing computer programs is made to foresee which mechanical assembly will next be required by the direct of the driver. 


\section{TYPES OF DCT}

The essential business DCT system to hit the market, DSG, and an expansive number of the resulting battling plans featured twin wet holds. This extraordinary system was prepared for transmitting torques up to $350 \mathrm{Nm}$, making it sensible for the Volkswagen Group's entire extent of diesel engines. The DCT thought has been moreover made since this time, with additional cutting-edge ages having the ability to manage 550Nm [12] (unit showed up in figure 1), 750Nm [13] and even $1250 \mathrm{Nm}$ in the Bugatti Veyron. Headway in various regions has provoked the arrangement of seven speed DCTs for prevalent vehicles, and furthermore insignificant exertion DCT answers for creating markets. The best assortment from the layout of the DSG structure, in any case, is the headway of the Ford dry twofold handle system for North America. Using twofold dry handles rather than wet grasps gives extended capability, regardless, the torque furthest reaches of the system is decreased[14]. This makes such structures unsuitable for use with diesel engines, which normally have high torque yields. With a torque farthest point of $280 \mathrm{Nm}$ this structure is suited to the associations' mid-range oil vehicles and is needed to help ask buyers to move a long way from surely understood anyway inefficient standard modified transmissions [15].

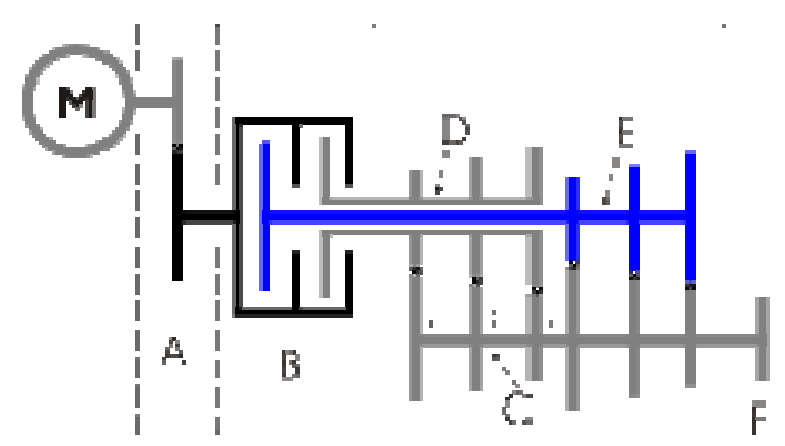

Figure 1: Representation of DCT system

\section{ADVANTAGES}

On a basic level, the DCT acts simply like a standard manual transmission:

- It has data and collaborator shafts to house mechanical assemblies, synchronizers and a grip. It doesn't have a grip pedal, since PCs, solenoids and water control do the authentic moving. Surely, even without a grip pedal, the driver can regardless "tell" the PC when to make a travel through paddles, gets or a gearshift [16].

- Driver experience is just a single of the various ideal conditions of a DCT. With up movements taking a basic 8 milliseconds, many feel that the DCT offers the most dominant enlivening of any vehicle accessible.

- It clearly offers smooth expanding speed by shedding the move stagger that runs with gearshifts in manual transmissions and even a couple of automatics. Best of all, it oversees drivers the benefit of picking whether they like to control the moving or let the PC do most of the work.

- Perhaps the most persuading ideal position of a DCT is upgraded mileage. Since control spill out of the engine to the transmission isn't interfered with, eco-benevolence augments essentially. A couple of experts state that a sixspeed DCT can pass on up to a 10 percent development in relative eco-agreeableness when stood out from a customary five-speed programmed. 


\section{CONCLUSIONS}

New environmental and eco-benevolence order joined with moves in contraptions and creating methodologies have actuated new robotized transmission progressions. The no doubt champ that will displace standard automatics and lift feature passage of mechanized transmissions will be the double grasp transmission (DCT). In perspective of the structure and standard of DCT, the vehicle prepare moving strategy is poor down in context of components and engine and grasp models are similarly settled, which set up system for the resulting itemizing of control technique of DCT move process. Through the cushioned control theory, independently from the power and economy point of view, the move plan in perspective of driver objective has been itemized, which develops the foundation for the resulting move proliferation illustrate. The control arrangement of the engine and handle and the exhaustive move control basis strategy are made in the ECT moving methodology.

\section{REFERENCES}

1. H. Wu, P. Walker, J. Wu, J. Liang, J. Ruan, and N. Zhang, "Energy management and shifting stability control for a novel dual input clutchless transmission system," Mech. Mach. Theory, vol. 135, pp. 298-321, May 2019.

2. P. Gao, P. D. Walker, H. Liu, S. Zhou, and C. Xiang, "Application of an adaptive tuned vibration absorber on a dual lay-shaft dual clutch transmission powertrain for vibration reduction,” Mech. Syst. Signal Process., vol. 121, pp. 725-744, Apr. 2019.

3. J. Huang, J. Zhang, W. Huang, and C. Yin, "Optimal Speed Synchronization Control With Disturbance Compensation for an Integrated Motor-Transmission Powertrain System,” J. Dyn. Syst. Meas. Control. ASME, vol. 141, no. 4, Apr. 2019.

4. J. Wang, J. Zhao, H. Zou, and J. Yao, "Design and simulation of a load-sensitive dual-speed transmission with a wide speed range,” J. Brazilian Soc. Mech. Sci. Eng., vol. 41, no. 4, Apr. 2019.

5. T. Lu, B. Zhou, J. Zhang, and X. Wang, “Clutch micro-slip control in gearshifts for dual clutch transmission,” Proc. Inst. Mech. Eng. Part K-Journal Multi-Body Dyn., vol. 233, no. 1, pp. 43-59, Mar. 2019.

6. Z. Zhao, J. Chen, X. Li, and D. Lei, "Downshift decision and process optimal control of dual clutch transmission for hybrid electric vehicles under rapid braking condition,” Mech. Syst. Signal Process., vol. 116, pp. 943-962, Feb. 2019.

7. Y. D. S. Liauw, M. Roozegar, T. Zou, A. Morozov, and J. Angeles, "A topology-change model of multi-speed transmissions in electric vehicles during gear-shifting," Mechatronics, vol. 55, pp. 151-161, Nov. 2018.

8. B. Heumesser, P. Fietkau, and B. Bertsche, "Rattle noises of dual clutch transmissions," Forsch. Im IngenieurwesenEngineering Res., vol. 82, no. 3, pp. 187-195, Sep. 2018.

9. K. Voelkel, F. Wohlleber, H. Pflaum, and K. Stahl, "Cooling performance of wet multi-plate disk clutches in modern applications," Forsch. Im Ingenieurwesen-Engineering Res., vol. 82, no. 3, pp. 197-203, Sep. 2018.

10. J. Cho, Y. Lee, W. Kim, and S. Jang, "Wet Single Clutch Engagement Behaviors in the Dual-Clutch Transmission System," Int. J. Automot. Technol., vol. 19, no. 3, pp. 463-472, Jun. 2018.

11. M. Rajabi-Vandechali, M. H. Abbaspour-Fard, and A. Rohani, "Development of a prediction model for estimating tractor engine torque based on soft computing and low cost sensors," Measurement, vol. 121, pp. 83-95, Jun. 2018.

12. Sreeraj, P., Kannan, T., \& Maji, S. (2013). Prediction and optimization of weld bead geometry in gas metal arc welding process using RSM and fmincon. Journal of Mechanical Engineering Research, 5(8), 154-165.

13. G. Li and D. Goerges, "Optimal control of the gear shifting process for shift smoothness in dual-clutch transmissions," Mech. Syst. Signal Process., vol. 103, pp. 23-38, Mar. 2018. 
14. A. Della Gatta, L. Iannelli, M. Pisaturo, A. Senatore, and F. Vasca, "A Dry Clutch Engagement Controller with Thermal Effects Compensation," in 2018 IEEE Conference On Control Technology And Applications (CCTA), 2018, pp. 1228-1233.

15. D. He, G. Wu, Y. Shi, and W. Yang, "Dynamic Performance Optimization of the Dual Clutch Transmission Based on Genetic Algorithm," in Proceedings of the ASME International Design Engineering Technical Conferences And Computers And Information In Engineering Conference, 2018, VOL 3, 2018.

16. Z. Jiang, Q. Liu, S. Dong, and H. Chen, "Launch Coordination Control Based on Twin-Clutch Torque Distribution for DCT Vehicle," IFAC Pap., vol. 51, no. 31, pp. 904-909, 2018.

17. J. Li, Q. Hu, C. Zong, T. Zhu, and Z. Zhang, "Vibration characteristics of two-stage planetary transmission system with thinwalled ring gear on elastic supports," in 2017 2ND International Conference On Mechatronics And Electrical Systems (ICMES 2017), 2018, vol. 339. 
